Article

\title{
Knockdown of WHIRLY1 Affects Drought Stress-Induced Leaf Senescence and Histone Modifications of the Senescence-Associated Gene HvS40
}

\author{
Bianka Janack ${ }^{1,+}$, Paula Sosoi ${ }^{2,+}$, Karin Krupinska ${ }^{3}$ and Klaus Humbeck ${ }^{1, *}$ \\ 1 Institute of Biology, Martin Luther University Halle-Wittenberg, Weinbergweg 10, 06120 Halle, Germany; \\ bianka.janack@pflanzenphys.uni-halle.de \\ 2 NIRDBS/Stejarul Research Centre for Biological Sciences, Alexandru cel Bun St., 6, 610004 Piatra Neamt, \\ Romania; ppp_paula_2007@yahoo.com \\ 3 Institute of Botany, Christian-Albrechts-University Kiel, Am Botanischen Garten 1-9, 24098 Kiel, Germany; \\ kkrupinska@bot.uni-kiel.de \\ * Correspondence: klaus.humbeck@pflanzenphys.uni-halle.de; Tel.: +49-345-55-26410 \\ + These authors contribute equally to this work.
}

Academic Editors: Salma Balazadeh and Milan S. Stankovic

Received: 4 December 2015; Accepted: 30 August 2016; Published: 6 September 2016

\begin{abstract}
The plastid-nucleus located protein WHIRLY1 has been described as an upstream regulator of leaf senescence, binding to the promoter of senescence-associated genes like HvS40. To investigate the impact of WHIRLY1 on drought stress-induced, premature senescence, transgenic barley plants with an RNAi-mediated knockdown of the HvWHIRLY1 gene were grown under normal and drought stress conditions. The course of leaf senescence in these lines was monitored by physiological parameters and studies on the expression of senescence- and drought stress-related genes. Drought treatment accelerated leaf senescence in WT plants, whereas WHIRLY 1 knockdown lines (RNAi-W1) showed a stay-green phenotype. Expression of both senescence-associated and drought stress-responsive genes, was delayed in the transgenic plants. Notably, expression of transcription factors of the WRKY and NAC families, which are known to function in senescence- and stress-related signaling pathways, was affected in plants with impaired accumulation of WHIRLY1, indicating that WHIRLY1 acts as an upstream regulator of drought stress-induced senescence. To reveal the epigenetic indexing of HvS40 at the onset of drought-induced senescence in WT and RNAi-W1 lines, stress-responsive loading with histone modifications of promoter and coding sequences of HvS40 was analyzed by chromatin immunoprecipitation and quantified by qRT-PCR. In the wildtype, the euchromatic mark H3K9ac of the HvS40 gene was low under control conditions and was established in response to drought treatment, indicating the action of epigenetic mechanisms in response to drought stress. However, drought stress caused no significant increase in H3K9ac in plants impaired in accumulation of WHIRLY1. The results show that WHIRLY1 knockdown sets in motion a delay in senescence that involves all aspects of gene expression, including changes in chromatin structure.
\end{abstract}

Keywords: drought stress; epigenetics; histone modification; HvS40; leaf senescence; WHIRLY1

\section{Introduction}

Leaf senescence is the final step of leaf development, characterized by decreasing photosynthetic activities and yellowing. During leaf senescence, nutritional resources are recycled for re-use in younger leaves and storage organs. In crop plants like barley, orderly progression of leaf senescence is an 
important determinant of yield. However, adverse environmental conditions, e.g., drought, can cause a premature onset of leaf senescence with inadequate recycling and major losses in yield. Despite the enormous worldwide crop losses by drought stress, the molecular mechanisms underlying drought stress-induced leaf senescence are still unclear.

Both the onset of developmental and stress-induced leaf senescence involves substantial reconstruction of mesophyll cells from sources of photosynthetic assimilates to transport forms of nutrients, generated by the degradation of the compounds of the photosynthetic machinery, in particular proteins [1]. These processes of re-construction are highly regulated and involve massive reprogramming of gene expression [2-5]. Whereas genes for photosynthetic functions are down-regulated, many genes are up-regulated during senescence and are called senescence-associated genes (SAGs; [5]). In addition, during stress-induced senescence, stress-responsive genes are induced. Many investigations revealed the concerted action of regulatory pathways involving hormones and transcription factors, which are connected to stress and senescence pathways, during transition of a photosynthetically active to a senescing leaf. Recently, it was shown that developmental leaf senescence is under the control of higher-order epigenetic mechanisms, influencing chromatin structure [6,7].

One potential upstream regulator of senescence-associated gene expression is the WHIRLY1 protein. In vitro it was shown to bind to the promoter of the senescence-associated barley gene HvS40, the expression of which is also induced by the pathogen Pyrenophora teres [8]. Previously, WHIRLY1 was reported to bind to the promoter of the PR10a gene in potato [9]. Interestingly, the major part of WHIRLY1 is located in chloroplast nucleoids associated with thylakoid membranes [10]. It has been proposed that upon changes in the redox state of the photosynthetic apparatus, the conformation of WHIRLY1 might be changed to enable translocation to the nucleus [11].

In the present report, we show that WHIRLY1 affects drought stress induction of premature leaf senescence and differential histone modifications of the senescence-associated gene $H v S 40$. The results suggest that WHIRLY1 is involved in regulation of drought stress-induced leaf senescence via epigenetic mechanisms.

\section{Results}

\subsection{WHIRLY1 Acts Upstream of Drought Stress-Induced Leaf Senescence}

Wildtype (WT) and plants of the barley line RNAi-W1, containing only traces of the WHIRLY1 protein [8], were grown under well-watered control and drought stress conditions, respectively. In control pots, the soil water content was kept at $60 \%$. To induce drought stress, irrigation was stopped four days after sowing (das), whereby the relative soil water content was successively decreased (Figure 1A). The drought stress caused premature senescence in WT whereas knockdown of HvWHIRLY1 reveals a delayed induction of premature senescence under drought conditions. Representative pictures of the barley primary leaves (Figure 1B) and physiological senescence parameters illustrate this. The chlorophyll content of drought-stressed plants started to decrease at 17 das in WT and 19 das in RNAi-W1 plants (Figure 1C). The decline in PS II efficiency began at 19 das in WT and at 22 das in transgenic line (Figure 1D). Plants with a reduced level of WHIRLY1 retained $77 \%$ of the starting value of PS II efficiency and $24 \%$ of chlorophyll at 25 das, when leaves of drought-stressed WT plants are already dead. 
(A)

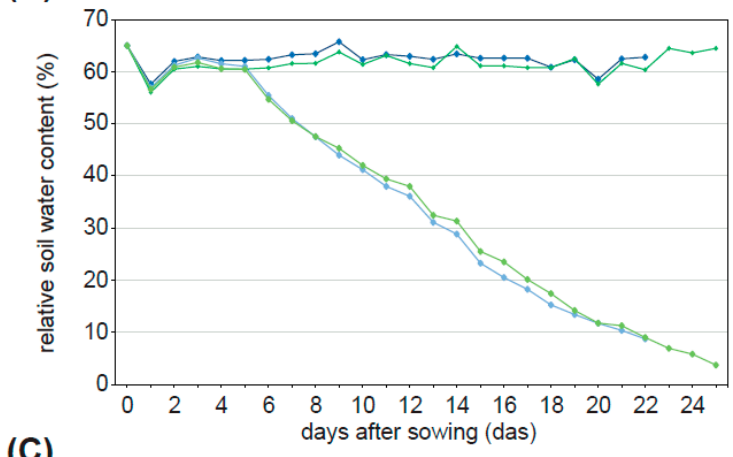

(C)

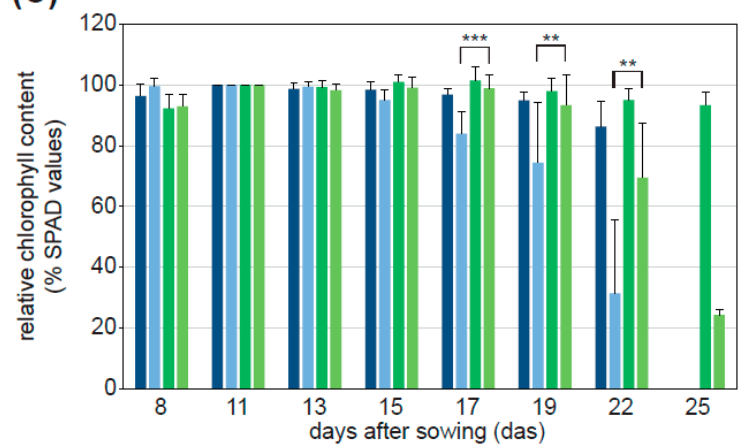

(B)

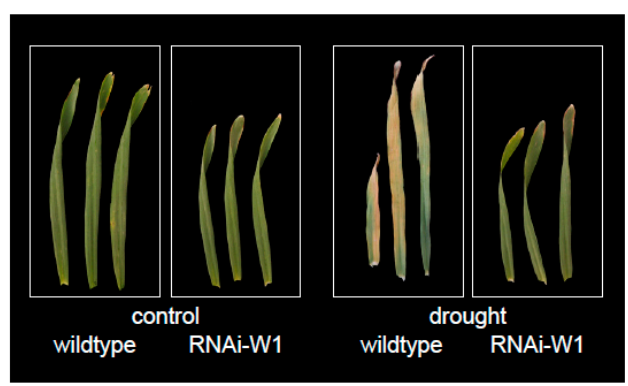

(D)

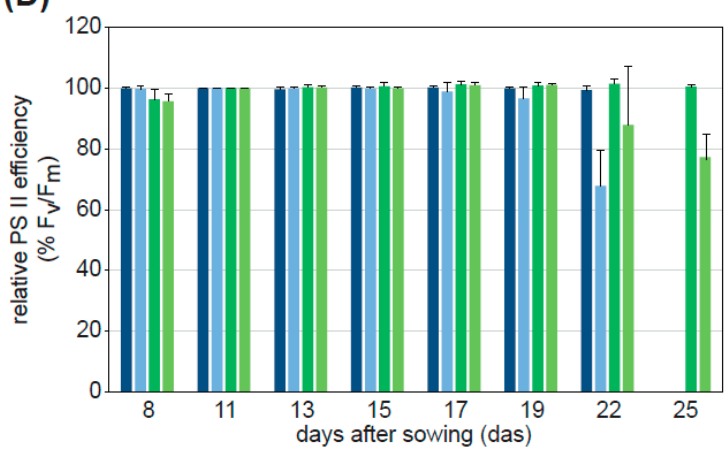

Figure 1. Drought stress-induced differences in the phenotypic appearance and physiological parameters of WT control (blue), WT drought (light blue), RNAi-W1 control (green), RNAi-W1 drought (light green) plants. (A) Relative soil water content in control pots and pots drying out with WT and RNAi-W1. To induce drought stress, irrigation was terminated at four das; (B) Representative pictures of WT and RNAi-W1 leaves under control and drought-stress conditions at 22 das; (C) Chlorophyll content (\% SPAD values) and (D) PS II efficiency $\left(\% \mathrm{~F}_{\mathrm{v}} / \mathrm{F}_{\mathrm{m}}\right)$ during drought stress in WT and RNAi-W1 leaves compared to controls. Data of 11 das were set as $100 \%$. Asterisks indicate statistically significant differences (paired Student's $t$-test $p$ values, ${ }^{* *} p<0.01 ; * * * p<0.001$ ) between drought-stressed WT and RNAi-W1. Data represent the average $( \pm \mathrm{SD})$ from at least three independent, individual experiments.

In accordance with the physiological data, drought stress treatment also affected the expression of genes either up- or down-regulated during senescence (Figure 2). GS2, encoding the plastid form of the glutamine synthetase, is a typical senescence down-regulated gene [12]. Expression of barley HvGS2 decreases during developmental senescence of primary leaves [7] but also during drought stress-induced, premature senescence (Figure 2A). HvS40, a senescence marker gene induced under dark-induced conditions and during developmental senescence [7,13-15], is highly induced during drought stress treatment (Figure 2B). Knockdown of WHIRLY1 clearly delayed the induction of HvS40 (Figure 2B). The drought stress treatment also affects the expression of stress-related genes such as HvDHN1 (encoding a dehydrin of the stress-related LEA protein family; $[16,17])$. Figure 2C shows that expression of this drought stress marker gene was induced during the stress treatment, but induction was delayed in drought stressed RNAi-W1. Especially WRKY and NAC transcription factors have been described to be involved in stress- and senescence-related pathways [5,18-21]. While HvWRKY12 and $H v W R K Y 33$ are induced in response to drought stress, HvWRKY21 is repressed (Figure 2D-F). As shown in Figure 2G,H the two NAC transcription factor genes HvNAC005 and HvNAC013 were also clearly up-regulated in response to drought stress. Induction of these stress- and senescence-related transcription factors, as well as the repression of HvWRKY21, was clearly delayed in plants with reduced levels of HvWHIRLY1. These data suggest that HvWHIRLY1 acts as a regulatory factor upstream of drought stress-induced, premature leaf senescence triggered by the concerted action of WRKY and NAC transcription factors. 

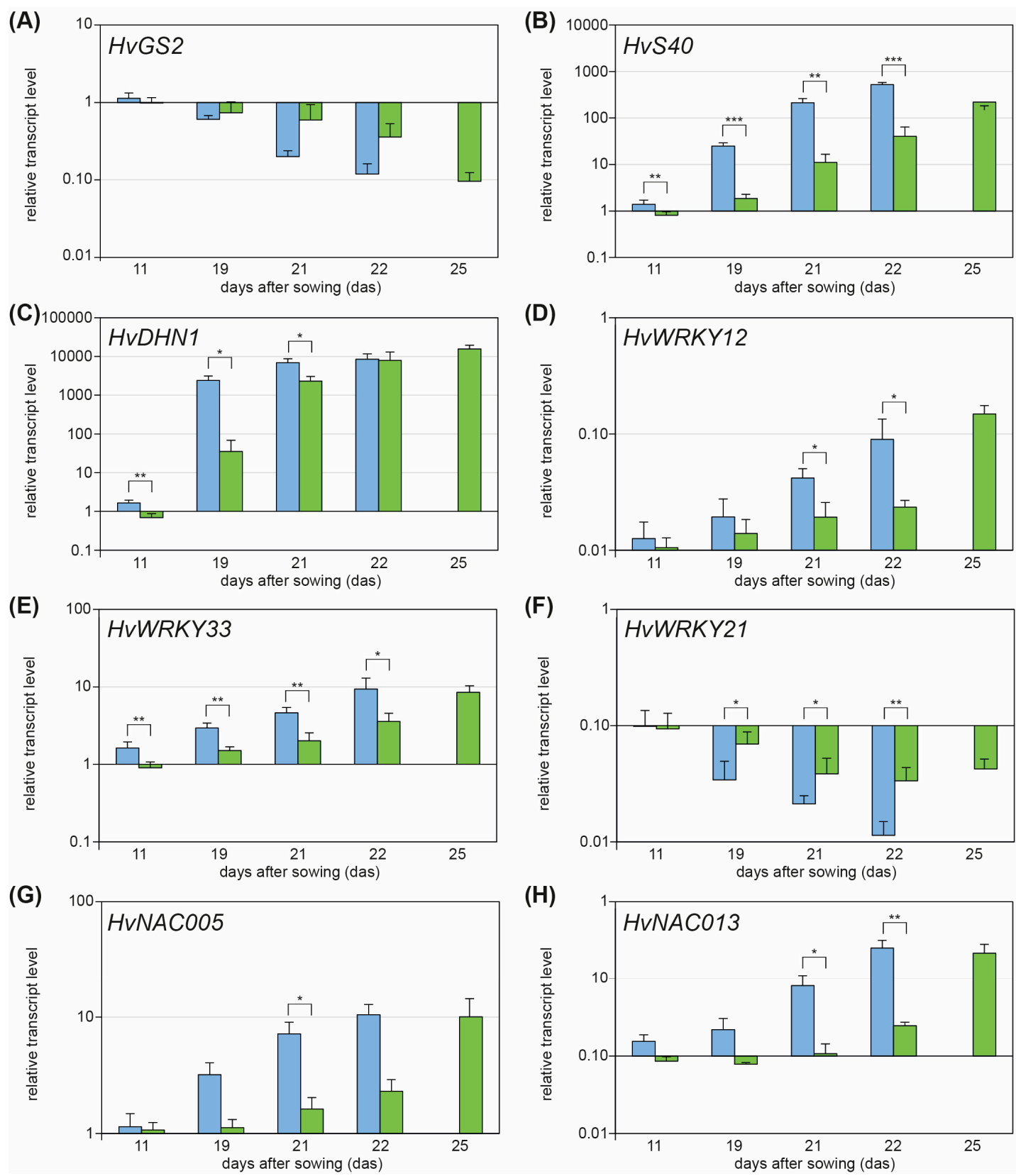

Figure 2. Relative transcript levels in drought-stressed WT (light blue) and RNAi-W1 (light green) plants of (A) senescence down-regulated gene HvGS2; (B) senescence-associated gene HvS40; (C) drought stress-related HvDHN1; (D,E,F) WRKY transcription factor genes HvWRKY12, HvWRKY33 and HvWRKY21 and $(\mathbf{G}, \mathbf{H})$ NAC transcription factor genes HvNAC005 and HvNAC013. At each data point, transcript levels in drought-stressed plants are compared to those in control plants. Asterisks indicate statistically significant differences (paired Student's $t$-test $p$ values, ${ }^{*} p<0.05 ;{ }^{* *} p<0.01$; *** $p<0.001$ ) between drought-stressed WT and RNAi-W1. Each data point represents the average $( \pm \mathrm{SD})$ from at least three independent, individual experiments.

\subsection{Knockdown of WHIRLY1 Affected Labeling of HvS40 with Histone Modification Marks}

Recent investigations showed senescence-specific alterations in histone modifications of senescence-associated genes (SAGs) [6,7]. Senescence and stress are closely linked; thus, drought stress can also induce the expression of several SAGs as displayed for $\mathrm{HvS40}$ (Figure 2B). This result is in accordance with the high expression of $\mathrm{HvS40}$ in response to abscisic acid [8]. Analysis under a 
shorter timescale (Figure 3A) showed that up-regulation of $H v S 40$ under these conditions started in parallel with the loss of chlorophyll (Figure 1C), at day 17 after sowing in WT plants. To investigate whether the induction of HvS40 during drought stress is also accompanied by differential histone modifications at its promoter and coding sequence, chromatin immunoprecipitation (ChIP) analyses with antibodies directed against the euchromatic mark H3K9ac (histone 3 lysine 9 acetylation) and the heterochromatic mark H3K9me2 (histone 3 lysine 9 dimethylation), respectively, were performed. Mature leaves of control plants were compared with drought-stressed WT leaves from 17 das, where HvS40 was not induced in well-watered control plants, but significantly induced in drought-stressed plants (Figure 3A). Quantification of levels of the two markers was performed via qRT-PCR using six primer pairs, covering specific sites in the promoter and coding sequence (positions in relation to the ATG codon I: -840 to $-718 \mathrm{bp}$, II: -369 to $-234 \mathrm{bp}$, III: -232 to $-92 \mathrm{bp}, \mathrm{IV}:-96$ to $+141 \mathrm{bp}$, $\mathrm{V}:+125$ to $+257 \mathrm{bp}$ and VI: +239 to $+334 \mathrm{bp}$ ) of HvS40 (Figure 3B). In Figure 3C, results are plotted for the heterochromatic mark, showing the ratio (D/C) in levels of H3K9me2 in drought-stressed (D) and control (C) leaf samples in WT and RNAi-W1. In addition, in Supplemental Figure S1, levels of labeling with $\mathrm{H} 3 \mathrm{~K} 9 \mathrm{me} 2$ are separately plotted for control and drought-stressed leaves in both, WT and RNAi-W1. These data show that in WT, drought stress causes a slight increase in H3K9me2 levels of HvS40. In RNAi-W1, however, drought stress caused no significant increase in labelling with H3K9me2. In accordance with the induction of $\mathrm{HvS40}$ (Figure 3A), the euchromatic mark H3K9ac is substantially increased in WT after drought treatment (see Figure 3 and Supplemental Figure S1), resulting in a significant increase in this mark at all promoter and coding sequence regions of HvS40 analyzed. However, since sonication yields DNA fragments in a range of different sizes, it is difficult to exactly resolve which regions of the gene have H3K9ac-modified histones. In contrast to the WT, in RNAi-W1, $\mathrm{H} 3 \mathrm{~K} 9 \mathrm{ac}$ levels are not increased (Figure 3D, ratio $=1$ ). This correlates with the finding that, in contrast to the WT, HvS40 is not induced above the control level in RNAi-W1 plants at 17 das (Figure 3A). Our data revealed that drought stress induces the establishment of euchromatic histone modifications of $H v S 40$, and that the function of WHIRLY1 might be connected to the stress and development related setting of epigenetic marks.

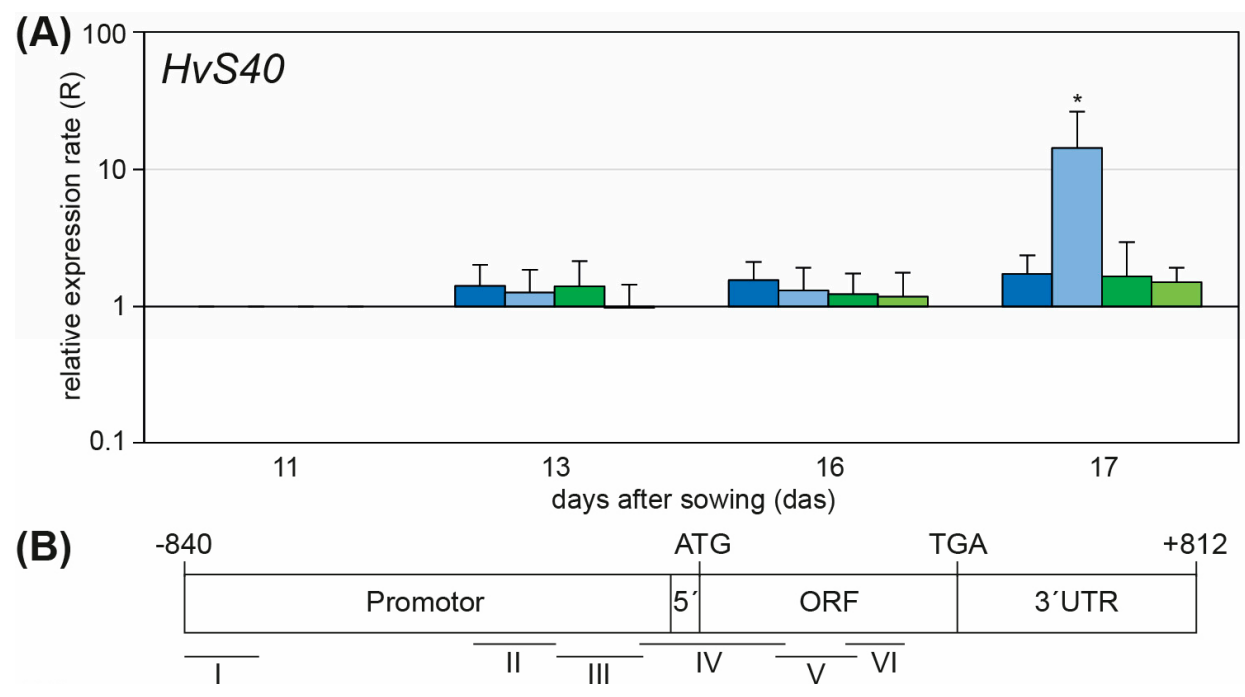

Figure 3. Cont. 


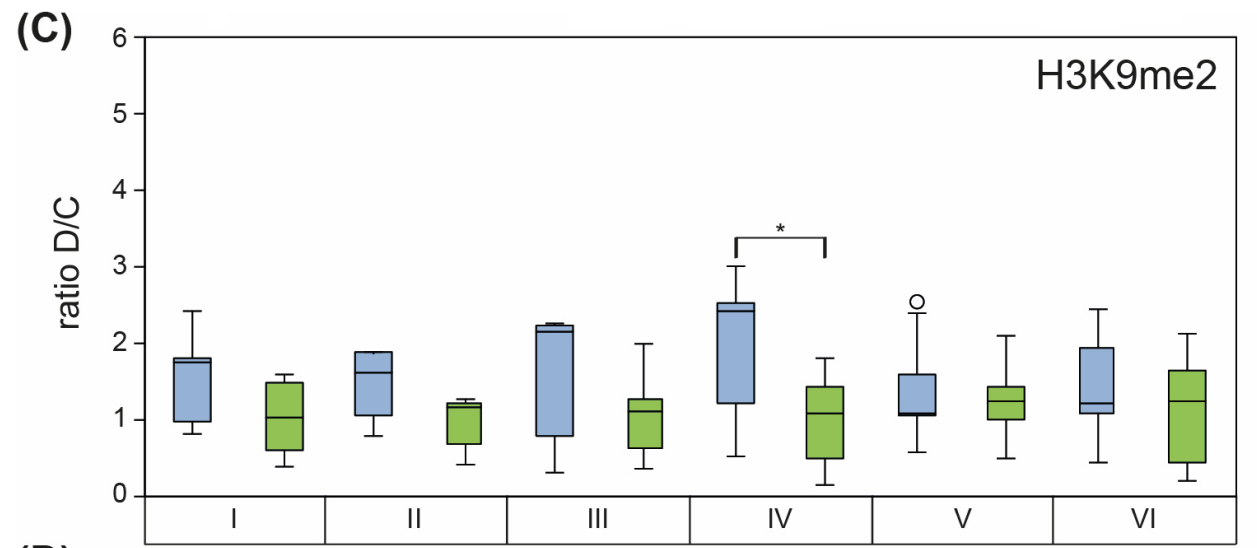

(D)

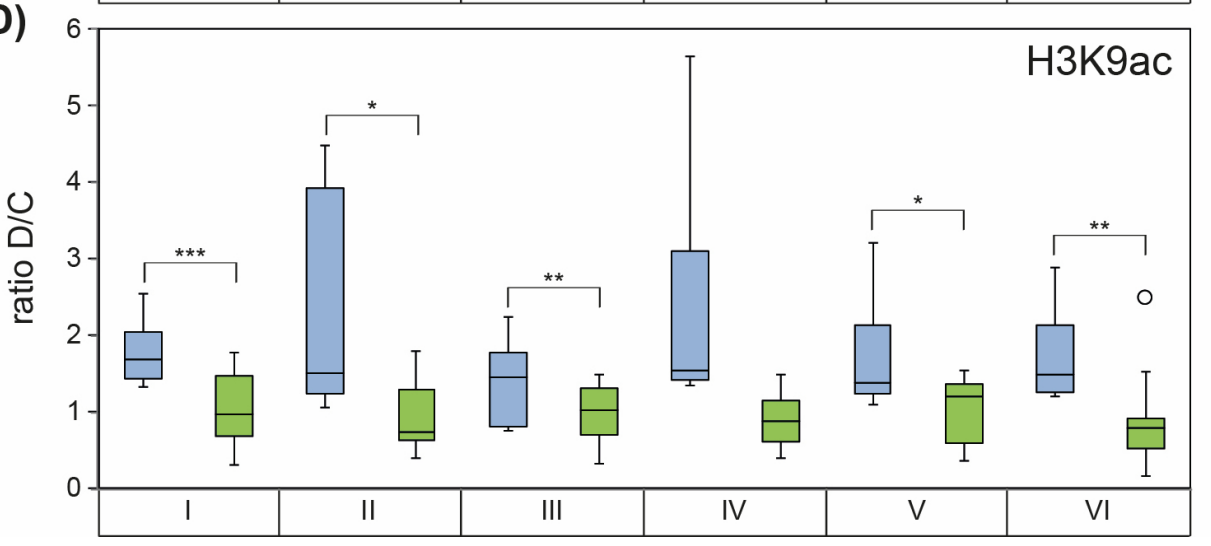

Figure 3. Alterations of histone modification levels of $H v S 40$ during drought stress-induced senescence of barley primary leaf. (A) Relative expression rate of HvS40 in primary leaves of WT control (blue), WT drought (light blue), RNAi-W1 control (green), RNAi-W1 drought (light green) normalized to the mature leaf (11 das); (B) Gene model showing analyzed regions of HvS40 in promoter (I-III), TLS (IV) and open reading frame (V and VI); (C,D) Drought stress-specific alterations (ratio drought/control $[\mathrm{D} / \mathrm{C}]$ ) in the level of histone 3 modifications K9me2 and K9ac at HvS40, shown as boxplots (central bar marking the median, lower and upper limits of the box marking the 25 th and 75 th percentiles, and the whiskers extending the 1.5 interquartile range from the box; data not included between the whiskers are dotted as outliers; WT in blue, RNAi-W1 in green). Asterisks indicate statistically significant differences between WT and RNAi-W1-7 (paired Student's t-test $p$ values, ${ }^{*} p<0.05$; ${ }^{* *} p<0.01 ;{ }^{* * *} p<0.001$ ). Each data point represents the average of at least three independent, individual experiments.

\section{Discussion}

Drought stress is a major reason for loss of yield. One consequence of drought stress is premature leaf senescence, which results in early down-regulation of photosynthesis, dismantling of the photosynthetic machinery and inefficient recycling of resources. The molecular response to drought is complex and involves components of abiotic stress response and senescence-associated signaling pathways, e.g., induction of the stress-related LEA gene HvDHN11 $[15,16]$ and the senescence-associated gene $\mathrm{HvS40}$ [12,14], the expression of which is highly up-regulated by ABA [8].

Several investigations show that in different plant species, including cereals, specific transcription factors are components of the regulatory pathway of drought stress-induced leaf senescence. In particular, those of the WRKY and NAC families act in this process [22-25].

Recently, for Arabidopsis thaliana [6], but also for barley [7], another superior level of regulation of the senescence program was identified. The authors could show an adjustment of chromatin status of senescence-associated genes via epigenetic mechanisms. It has been demonstrated that especially euchromatic histone modification marks like H3K4me2/3 and H3K9ac are established in respective promoter and coding regions of senescence-associated genes (AtWRKY53 and HvS40), 
indicating the action of epigenetic mechanisms in regulation of leaf senescence. An increasing number of investigations showed that various types of stress responses are also under the control of epigenetic mechanisms [26,27]. In this study, a differential setting of histone modification marks in response to drought stress at promoter and coding sequences of the senescence-associated barley gene $\mathrm{HvS} 40$ has been demonstrated. Interestingly, in the early response to drought stress, the euchromatic mark H3K9ac was observed to be established at promoter and coding regions of HvS40. Establishment of H3K9ac is known to open chromatin structure by changing the charge distribution and thereby allowing access of regulatory proteins to DNA, resulting in induction of transcription [28-31]. Similar observations have been reported for stress-related genes in Arabidopsis thaliana and in rice, where euchromatic marks such as the methylation pattern at H3K4 are set when plants are exposed to drought [32-34].

Interestingly, in a recent genome-wide study in Arabidopsis thaliana, a positive correlation between gain of H3K4me3 and H3K9ac and the expression of senescence up-regulated genes could be proven [35]. The authors could show an increase in H3K9ac level for Arabidopsis At1g29640, a homolog of barley HvS40. After drought treatment a slight, however much less pronounced, increase in H3K9me2 was observed. This is known in Arabidopsis thaliana to be associated with constitutive heterochromatic regions [29]. While crop plants in general show higher H3K9me2 levels compared to Arabidopsis [36], its function in euchromatic regions is not clearly solved.

In this study, plants with impaired accumulation of WHIRLY1 were shown to have delayed senescence during drought stress. In addition, we can show that impaired accumulation of WHIRLY 1 affects labeling of the senescence-associated gene HvS40 with the euchromatic mark H3K9ac. Taken together, the results indicate that WHIRLY1 is involved in the signaling pathways during stress-induced senescence acting on epigenetic mechanisms.

WHIRLY1 is a DNA binding protein located in chloroplasts as well as in the nucleus [10] and in transplastomic tobacco plants, was shown to translocate from the organelle to the nucleus [37]. In chloroplasts, it has been identified as a nucleoid-associated protein [38-40]. In the nucleus, it has been found in association with promoters of the PR10a gene of potato [9] and of $\mathrm{HvS40}$ [8]. A delay of senescence in response to stress factors in plants with a reduced amount of WHIRLY1 suggests that WHIRLY1 is required for detection of stress, i.e., drought and high irradiance. In Arabidopsis seedlings, it has been shown that WHIRLY1 located inside the plastid is required for sensing of exogenously applied salicylic acid and abscisic acid [41]. These hormones are major upstream regulators of pathogen and drought stress responses, respectively $[42,43]$. Based on these findings, it has been hypothesized that WHIRLY1 located in chloroplast nucleoids bound to thylakoid membranes might act as a sensor and a communicator of hormone-dependent and stress-related redox changes in the photosynthetic apparatus [11].

Although WHIRLY1 has been shown to bind to promoters of HvS40 and PR genes, the molecular mechanism of WHIRLY1 action in the nucleus is not clear. In contrast to conventional transcription factors, WHIRLY1 binds preferentially to single-stranded DNA and RNA [44]. Interestingly, electron microscopy using immunogold labeling revealed that WHIRLY1 in the nucleus was preferentially located in dense, heterochromatic areas [10]. This finding is in accordance with the observation that WHIRLY1 in chloroplasts promotes the compactness of nucleoids [8]. It is hence proposed that WHIRLY1, by interaction with DNA (in plastid and nucleus), affects DNA structure. We hypothesize that WHIRLY1, by interaction with senescence-associated genes, is able to modulate epigenetic mechanisms, which determine local chromatin structure, i.e., histone modifications, DNA methylation and/or chromatin remodeling. This hypothesis has to be tested in future experiments

\section{Experimental Section}

\subsection{Plant Material and Growth Conditions}

Seeds of barley wildtype (Hordeum vulgare L. cv Golden Promise) and transgenic barley plants of the line RNAi-W1, produced by RNAi-mediated knockdown of the WHIRLY1 gene [45], were 
germinated on wet tissues for $48 \mathrm{~h}$ at $4{ }^{\circ} \mathrm{C}$ and $24 \mathrm{~h}$ at room temperature in darkness. After germination, barley seedlings (10 plants per pot) were sown in 'Mitscherlich' pots, each containing $1.3 \mathrm{~kg}$ soil (ED73, Einheitserdewerk Hameln A. Stangenberg GmbH, Sinntal, Germany, http:/ / www.einheitserde.de) and were grown in a phytochamber under long-day conditions ( $16 \mathrm{~h}$ with light intensity of $400 \mu \mathrm{E} \cdot \mathrm{m}^{-2} \cdot \mathrm{s}^{-1}$ at $21{ }^{\circ} \mathrm{C}$ and $8 \mathrm{~h}$ in the dark at $18{ }^{\circ} \mathrm{C}$, humidity of about $60 \%$ ). Control plants of wildtype and the RNAi-W1 line were well watered. Their soil water content was kept at $60 \%$ throughout plant development. For the drought stress treatment, irrigation was terminated four days after sowing (das), allowing the soil to dry out. All measurements were performed using primary leaves (the first leaf after the coleoptile). For gene expression analysis, complete primary leaf blades from control and treated plants were collected, immediately frozen in liquid nitrogen and stored at $-80{ }^{\circ} \mathrm{C}$. For analyzing histone modification patterns by chromatin immunoprecipitation (ChIP), $1 \mathrm{~g}$ of total primary leaf blades of each plant line were harvested, fixed with formaldehyde, frozen in liquid nitrogen and stored at $-80^{\circ} \mathrm{C}$. Collection of leaf material took place in the middle of the light period. Data were obtained from at least three independent sowings comparing WT and RNAi plants during growth under control and drought conditions.

\subsection{Physiological Measurements}

Measurement of physiological parameters (chlorophyll content and PS II efficiency) of leaf material took place in the middle of the light period. Measured values from 11 das, when primary leaves reached the mature stage of development, were set to $100 \%$.

\subsubsection{Chlorophyll Content}

Determination of relative chlorophyll content per unit leaf area was carried out by using a SPAD (Soil Plant Analysis Development) analyzer (Konica Minolta Sensing Europe, Munich, Germany, http:/ / www.konicaminolta.eu). Transmittance of red light $(650 \mathrm{~nm})$ and infrared $(940 \mathrm{~nm})$ radiation is measured noninvasively on intact leaves. Relative SPAD values are related to the chlorophyll content in a linear manner [46]. Each data point represents the average of at least three independent biological replicates with 20 independent measurements at each tip, middle and base of primary leaves.

\subsubsection{PS II Efficiency}

To determine PS II efficiency $\left(\mathrm{F}_{\mathrm{v}} / \mathrm{F}_{\mathrm{m}}\right)$, as a measure of the quantum yield of PS II [47], chlorophyll fluorescence was measured with a Photosynthesis Yield Analyzer (Mini-PAM, Walz $\mathrm{GmbH}$, Effeltrich, Germany, http:/ / www.walz.com) using the pulse amplitude modulation (PAM) method [48]. Measurements were executed at the mid position of 20-min dark-adapted primary leaves. Each data point represents the average of at least three independent biological replicates with 20 independent measurements at the mid position of primary leaves.

\subsection{Gene Expression}

From primary leaves of WT and RNAi-W1 of control and stress-treated plants, total RNA was isolated with trizol as described by Chomczynski and Mackey [49]. By gel electrophoresis (1\% TAE agarose gel), integrity of extracted RNA was verified. To prevent contamination by genomic DNA, RNA samples were treated with RNase-free-DNaseI (Roche-Diagnostics GmbH, Mannheim, Germany, www.roche.com/diagnostics). Synthesis of the first-strand cDNA was executed as described in operating manual by reverse transcription of $1 \mu \mathrm{g}$ of total RNA with RevertAid H Minus Reverse Transcriptase (Thermo Fisher Scientific, Inc. Waltham, MA, USA, www.thermoscientificbio.com) in a volume of $20 \mu \mathrm{L}$. qRT-PCR was performed in $20 \mu \mathrm{L}$ containing $1 \times$ Platinum $^{\circledR}$ SYBR $^{\circledR}$ Green qPCR SuperMix-UDG (life technologies ${ }^{\mathrm{TM}}$, now part of Thermo Fisher Scientific, Inc. Waltham, MA, USA, www.lifetechnologies.com), $0.2 \mu \mathrm{M}$ each gene specific primer (see Supplemental Table S1), $10 \mu \mathrm{M}$ fluorescein (Bio-Rad Laboratories, Inc., Göttingen, Germany, www.biorad.com) for well-factor calibration and $1 \mu \mathrm{L}$ of diluted (1:4) template cDNA. Primers specific for the HvACTIN intron were 
used to validate the absence of genomic DNA. No-template controls were carried out to exclude the amplification of unspecific products. PCR was executed with MyiQ ${ }^{\mathrm{TM}} 2$ System from Bio-Rad Laboratories, Inc. (Göttingen, Germany). Relative expression rate of genes of interest were calculated by $2^{-\Delta \Delta C_{T}}$ method [50]. Thereby, expression data of genes of interest (GOI) of control $\left(\Delta C_{\text {Tcontrol }}\right.$ $\left.=\mathrm{C}_{\mathrm{TGOI}}-\mathrm{C}_{\mathrm{THvACTIN}}\right)$ and drought-stressed $\left(\Delta \mathrm{C}_{\text {Tdrought }}=\mathrm{C}_{\mathrm{TGOI}}-\mathrm{C}_{\mathrm{THvACTIN}}\right)$ plants of WT and RNAi-W1 were normalized to the reference gene HvACTIN expression. In addition, HvACTIN, HvPP2A was also tested as a reference gene [7] showing similar constant values as HvActin (data not shown), but is not as stable in Hordeum vulgare L. cv Golden Promise. The values were further normalized to the expression of the gene of interest in control plants at the same time point $\left(2^{-\left(\Delta C_{T} \text { drought }-\Delta C_{\mathrm{T}} \text { control }\right)}\right)$. Each data point represents the average of measurements of three independent biological replicates.

\subsection{Chromatin Immunoprecipitation}

ChIP was performed as described by Gendrel et al. [51] and Ay et al. [6] with some modifications. From WT and RNAi-W1 control and drought-stressed plants, $1 \mathrm{~g}$ of primary leaves were harvested at 17 das and cross-linked (0.4 M sucrose, $10 \mathrm{mM}$ Tris- $\mathrm{HCl}$ (pH 8), $1 \mathrm{mM}$ Na-EDTA, $1 \mathrm{mM}$ PMSF and $1 \%$ formaldehyde [52]) for $10 \mathrm{~min}$ at $4{ }^{\circ} \mathrm{C}$ by vacuum infiltration (18-20 mmHg). The cross-linking reaction was then stopped by adding glycine (final concentration of $0.1 \mathrm{M}$ ) and another 5 min of vacuum incubation. To extract chromatin, the nuclei were isolated and re-suspended in nuclei lysis buffer (50 mM Tris- $\mathrm{HCl}$ (pH 8), 10 mM Na-EDTA, 1\% SDS, $0.1 \mathrm{mM}$ PMSF and Protease Inhibitor Cocktail (Roche, Mannheim, Germany). Chromatin was sheared with ultra sound using Bioruptor UCD-200 (Europe-Diagenode, Liége, Belgium, www.diagenode.com) to an average fragment size of $300 \mathrm{bp}$, which was checked by gel electrophoresis (1\% TAE agarose gel) for each biological replicate. Immunoprecipitation was performed overnight at $4{ }^{\circ} \mathrm{C}$ with antibodies against $\mathrm{H} 3 \mathrm{~K} 9 \mathrm{me} 2$ (ab1220) and H3K9ac (ab10812) obtained from Abcam (Cambridge, UK, http:/ / www.abcam.com). In addition, input DNA control (representing total amount of DNA) and no-antibody control (mock) were executed. To isolate and clean immunoprecipitated DNA NucleoSpin®Gel and PCR Clean-up kit (Macherey \& Nagel, Düren, Germany, www.mn-net.com) was used. The amount of precipitated DNA was quantified by qRT-PCR. qRT-PCR reactions were performed in a total volume of $20 \mu \mathrm{L}$ containing $1 \times$ Platinum $^{\circledR}$ SYBR $^{\circledR}$ Green qPCR SuperMix-UDG (life technologies ${ }^{\mathrm{TM}}$, now part of Thermo Fisher Scientific, Inc. Waltham, MA, USA), $0.2 \mu \mathrm{M}$ each gene-specific primer (see Supplemental Table S1), $10 \mu \mathrm{M}$ fluorescein (Bio-Rad Laboratories, Inc., Göttingen, Germany) for well-factor calibration and $5 \mu \mathrm{L}$ precipitated template DNA. To exclude the amplification of unspecific products, no-template controls were carried out. PCR was executed with the MyiQ ${ }^{\mathrm{TM}} 2$ System from Bio-Rad. To calculate the percentage input, input DNA control was set to $100 \%$ and a standard curve was performed with a dilution series $(0.12 \%, 0.06 \%, 0.03 \%, 0.015 \%, 0.0075 \%, 0.00375 \%$ and $0.001875 \%)$ for each gene-specific primer pair. Mock values, which were below $0.1 \%$ of input DNA, were subtracted from IP samples. Subsequently, drought-stressed (D) results were divided by the results of untreated mature control (C) primary leaves (ratio D/C) for WT and RNAi-W1, respectively. Each data point represents the average of at least three independent biological replicates.

\subsection{Primer Design}

Primers for expression and chromatin immunoprecipitation analyses were designed by using the PrimerSelectTM tool (Lasergene®from DNAStar, Inc.; Madison, WI, USA, www.dnastar.com). All Primer sequences were verified to be specific for the corresponding gene by using the BLAST tools provided by the National Center for Biotechnology Information (http:/ / www.ncbi.nlm.nih.gov) and the Leibniz Institute of Plant Genetics and Crop Plant Research (IPK) (http:/ / webblast.ipk-gatersleben. de/barley/). 


\subsection{Accession Number}

Sequence data for a Hordeum vulgare subsp. vulgare genomic clone of HvS40 can be found in the GenBank data libraries under accession number FI496079.1.

\section{Conclusions}

WHIRLY1 is an upstream regulator of developmental and drought stress-induced leaf senescence. Its knockdown affects expression of the senescence-associated gene HvS40. During drought stress-induced senescence, the euchromatic, transcription activating histone modification H3K9ac is established at promoter and coding sequence of HvS40 in wildtype, but not in WHIRLY1 knockdown line, indicating WHIRLY1-dependent regulation of drought stress- and senescence-related transcriptional reprogramming via epigenetic mechanisms.

Supplementary Materials: The following are available online at www.mdpi.com/2223-7747/5/3/37/s1.

Acknowledgments: This work was supported by the German Research Foundation (DFG, Hu 376/13-2), the German Federal Ministry of Food and Agriculture (\#22015209, FNR) and the EU (Marie Curie Initial Training Network "Crop Life").

Author Contributions: Klaus Humbeck, Bianka Janack and Paula Sosoi conceived and designed the experiments; Paula Sosoi and Bianka Janack performed the experiments; Paula Sosoi and Bianka Janack analyzed the data; Karin Krupinska contributed the RNAi-W1 lines; Klaus Humbeck, Bianka Janack, Paula Sosoi and Karin Krupinska wrote the paper.

Conflicts of Interest: The authors declare no conflict of interest.

\section{References}

1. Krupinska, K.; Humbeck, K. Senescence processes and their regulation. Plant Biol. 2008, 10, 1-3. [CrossRef] [PubMed]

2. Buchanan-Wollaston, V.; Page, T.; Harrison, E.; Breeze, E.; Lim, P.O.; Nam, H.G.; Lin, J.F.; Wu, S.H.; Swidzinski, J.; Ishizaki, K.; et al. Comparative transcriptome analysis reveals significant differences in gene expression and signaling pathways between developmental and dark/starvation induced senescence in Arabidopsis. Plant J. 2005, 42, 567-585. [CrossRef] [PubMed]

3. Balazadeh, S.; Riano-Pachón, D.M.; Mueller-Roeber, B. Transcription factors regulating leaf senescence in Arabidopsis thaliana. Plant Biol. 2008, 10, 63-75. [CrossRef] [PubMed]

4. Breeze, E.; Harrison, E.; McHattie, S.; Hughes, L.; Hickman, R.; Hill, C.; Kiddle, S.; Kim, Y.S.; Penfold, C.A.; Jenkins, D.; et al. High-Resolution temporal profiling of transcripts during Arabidopsis leaf senescence reveals a distinct chronology of processes and regulation. Plant Cell 2011, 23, 873-894. [CrossRef] [PubMed]

5. Guo, Y.; Gan, S.S. Convergence and divergence in gene expression profiles induced by leaf senescence and 27 senescence-promoting hormonal, pathological and environmental stress treatments. Plant Cell Environ. 2012, 35, 644-655. [CrossRef] [PubMed]

6. Ay, N.; Irmler, K.; Fischer, A.; Uhlemann, R.; Reuter, G.; Humbeck, K. Epigenetic programming via histone methylation at WRKY53 controls leaf senescence in Arabidopsis thaliana. Plant J. 2009, 58, 333-346. [CrossRef] [PubMed]

7. Ay, N.; Janack, B.; Fischer, A.; Reuter, G.; Humbeck, K. Alterations of histone modifications at the senescence-associated gene HvS40 in barley during senescence. Plant Mol. Biol. 2015, 89, 127-141. [CrossRef] [PubMed]

8. Krupinska, K.; Daehnhardt, D.; Fischer-Kilbienski, I.; Kucharewicz, W.; Scharrenberg, C.; Trösch, M.; Buck, F. Identification of WHIRLY1 as a factor binding to the promoter of the stress- and senescence-associated gene HvS40. J. Plant Growth Regul. 2014, 33, 91-105. [CrossRef]

9. Desveaux, D.; Després, C.; Joyeux, A.; Subramaniam, R.; Brisson, N. PBF-2 is a novel single-stranded DNA binding factor implicated in PR-10a gene activation in potato. Plant Cell 2000, 12, 1477-1489. [CrossRef] [PubMed]

10. Grabowski, E.; Miao, Y.; Mulisch, M.; Krupinska, K. Single-Stranded DNA-binding protein Whirly1 in barley leaves is located in plastids and the nucleus of the same cell. Plant Physiol. 2008, 147, 1800-1804. [CrossRef] [PubMed] 
11. Foyer, C.H.; Karpinska, B.; Krupinska, K. The functions of WHIRLY1 and REDOX-RESPONSIVE TRANSCRIPTION FACTOR 1 in cross tolerance responses in plants: A hypothesis. Philos. Trans. R. Soc. B 2014, 369. [CrossRef] [PubMed]

12. Solorzano, F. Glutamine Synthetase Gene Regulation and Expression during Leaf Senescence. Ph.D. Thesis, New Mexico State University, Las Cruces, NM, USA, 10 May 2010.

13. Becker, W.; Apel, K. Differences in gene expression between natural and artificially induced leaf senescence. Planta 1993, 189, 74-79. [CrossRef]

14. Humbeck, K.; Quast, S.; Krupinska, K. Functional and molecular changes in the photosynthetic apparatus during senescence of flag leaves from field-grown barley plants. Plant Cell Environ. 1996, 19, 337-344. [CrossRef]

15. Krupinska, K.; Haussuehl, K.; Schaefer, A.; van der Kooij, T.A.W.; Leckband, G.; Loerz, H.; Falk, J. A novel nucleus-targeted protein is expressed in barley leaves during senescence and pathogen infection. Plant Physiol. 2002, 130, 1172-1180. [CrossRef] [PubMed]

16. Suprunova, T.; Krugman, T.; Fahima, T.; Chen, G.; Shams, I.; Korol, A.; Nevo, E. Differential expression of dehydrin genes in wild barley Hordeum spontaneum associated with resistance to water deficit. Plant Cell Environ. 2004, 27, 1297-1308. [CrossRef]

17. Tommasini, L.; Svensson, J.T.; Rodriguez, E.M.; Wahid, A.; Malatrasi, M.; Kato, K.; Wanamaker, J.R.; Close, T.J. Dehydrin gene expression provides an indicator of low temperature and drought stress: Transcriptome-Based analysis of barley (Hordeum vulgare L.). Funct. Integr. Genomics 2008, 8, 387-405. [CrossRef] [PubMed]

18. Chen, L.; Song, Y.; Li, S.; Zhang, L.; Zou, C.; Yu, D. The role of WRKY transcription factors in plant abiotic stresses. Biochim. Biophys. Acta 2012, 1819, 120-128. [CrossRef] [PubMed]

19. Nakashima, K.; Takasaki, H.; Mizoi, J.; Shinozaki, K.; Yamaguchi-Shinozaki, K. NAC transcription factors in plant abiotic stress responses. Biochim. Biophys. Acta 2012, 1819, 97-103. [CrossRef] [PubMed]

20. Christiansen, M.W.; Gregersen, P.L. Members of the barley NAC transcription factor gene family show differential co-regulation with senescence-associated genes during senescence of flag leaves. J. Exp. Bot. 2014. [CrossRef] [PubMed]

21. Hollmann, J.; Gregersen, P.L.; Krupinska, K. Identification of predominant genes involved in regulation and execution of senescence-associated nitrogen remobilization in flag leaves of field grown barley. J. Exp. Bot. 2014. [CrossRef] [PubMed]

22. Tripathi, P.; Rabara, R.C.; Rushton, P.J. A systems biology perspective on the role of WRKY transcription factors in drought responses in plants. Planta 2014, 239, 255-266. [CrossRef] [PubMed]

23. Puranik, S.; Sahu, P.P.; Srivastava, P.S.; Prasad, M. NAC proteins: Regulation and role in stress tolerance. Trends Plant Sci. 2012, 17, 369-381. [CrossRef] [PubMed]

24. Okay, S.; Derelli, E.; Unver, T. Transcriptome-Wide identification of bread wheat WRKY transcription factors in response to drought stress. Mol. Genet. Genomics 2014, 289, 765-781. [CrossRef] [PubMed]

25. Le, D.T.; Nishiyama, R.; Watanabe, Y.; Mochida, K.; Yamaguchi-Shinozaki, K.; Shinozaki, K.; Phan Tran, L.S. Genome-Wide survey and expression analysis of the plant-specific NAC transcription factor family in soybean during development and dehydration stress. DNA Res. 2011, 18, 263-276. [CrossRef] [PubMed]

26. Kim, J.M.; Sasaki, T.; Ueda, M.; Sako, K.; Seki, M. Chromatin changes in response to drought, salinity, heat, and cold stresses in plants. Front. Plant Sci. 2015. [CrossRef] [PubMed]

27. Luo, M.; Liu, X.; Singh, P.; Cui, Y.; Zimmerli, L.; Wu, K. Chromatin modifications and remodeling in plant abiotic stress responses. Biochim. Biophys. Acta 2012, 1819, 129-136. [CrossRef] [PubMed]

28. Pfluger, J.; Wagner, D. Histone modifications and dynamic regulation of genome accessibility in plants. Curr. Opin. Plant. Biol. 2007, 10, 645-652. [CrossRef] [PubMed]

29. Zhou, J.; Wang, X.; He, K.; Charron, J.B.F.; Elling, A.A.; Deng, X.W. Genome-Wide profiling of histone H3 lysine 9 acetylation and dimethylation in Arabidopsis reveals correlation between multiple histone marks and gene expression. Plant Mol. Biol. 2010, 72, 585-595. [CrossRef] [PubMed]

30. Song, Y.; Ji, D.; Li, S.; Wang, P.; Li, Q.; Xiang, F. The dynamic changes of DNA methylation and histone modifications of salt responsive transcription factor genes in soybean. PLoS ONE 2012. [CrossRef] [PubMed]

31. Du, Z.; Li, H.; Wei, Q.; Zhao, X.; Wang, C.; Zhu, Q.; Yi, Y.; Xu, W.; Liu, X.S.; Jin, W.; et al. Genome-wide analysis of histone modifications: H3K4me2, H3K4me3, H3K9ac, and H3K27ac in Oryza sativa L. Japonica. Mol. Plant 2013, 6, 1463-1472. [CrossRef] [PubMed] 
32. Van Dijk, K.; Ding, Y.; Malkaram, S.; Riethoven, J.J.M.; Liu, R.; Yang, J.; Laczko, P.; Chen, H.; Xia, Y.; Ladunga, I.; et al. Dynamic changes in genome-wide histone H3 lysine 4 methylation patterns in response to dehydration stress in Arabidopsis thaliana. BMC Plant Biol. 2010, 10. [CrossRef] [PubMed]

33. Kim, J.M.; To, T.K.; Ishida, T.; Matsui, A.; Kimura, H.; Seki, M. Transition of chromatin status during the process of recovery from drought stress in Arabidopsis thaliana. Plant Cell Physiol. 2012, 53, 847-856. [CrossRef] [PubMed]

34. Zong, W.; Zhong, X.; You, J.; Xiong, L. Genome-Wide profiling of histone H3K4-tri-methylation and gene expression in rice under drought stress. Plant Mol. Biol. 2013, 81, 175-188. [CrossRef] [PubMed]

35. Brusslan, J.A.; Bonora, G.; Rus-Canterbury, A.M.; Tariq, F.; Jaroszewicz, A.; Pellegrini, M. A genome-wide chronological study of gene expression and two histone modifications, H3K4me3 and H3K9ac, during developmental leaf senescence. Plant Phys. 2015, 168, 1246-1261. [CrossRef] [PubMed]

36. West, P.T.; Li, Q.; Ji, L.X.; Eichten, S.R.; Song, J.W.; Vaughn, M.W.; Schmitz, R.J.; Springer, N.M. Genomic distribution of H3K9me2 and DNA methylation in a maize genome. PLoS ONE 2014, 9. [CrossRef] [PubMed]

37. Isemer, R.; Mulisch, M.; Schaefer, A.; Kirchner, S.; Koop, H.U.; Krupinska, K. Recombinant Whirly1 translocates from transplastomic chloroplasts to the nucleus. FEBS Lett. 2012, 586, 85-88. [CrossRef] [PubMed]

38. Pfalz, J.; Liere, K.; Kandlbinder, A.; Dietz, K.-J.; Oelmueller, R. pTAC2, -6, and -12 are components of the transcriptionally active plastid chromosome that are required for plastid gene expression. Plant Cell 2006, 18, 176-197. [CrossRef] [PubMed]

39. Majeran, W.; Friso, G.; Asakura, Y.; Qu, X.; Huang, M.; Ponnala, L.; Watkins, K.P.; Barkan, A.; van Wijk, K.J. Nucleoid-Enriched proteomes in developing plastids and chloroplasts from maize leaves: A new conceptual framework for nucleoid functions. Plant Physiol. 2012, 158, 156-189. [CrossRef] [PubMed]

40. Melonek, J.; Mulisch, M.; Schmitz-Linneweber, C.; Grabowski, E.; Hensel, G.; Krupinska, K. Whirly1 in chloroplasts associates with intron containing RNAs and rarely co-localizes with nucleoids. Planta 2010, 232, 471-481. [CrossRef] [PubMed]

41. Isemer, R.; Krause, K.; Grabe, N.; Kitahata, N.; Asami, T.; Krupinska, K. Plastid located WHIRLY1 enhances the responsiveness of Arabidopsis seedlings toward abscisic acid. Front. Plant Sci. 2012, 3. [CrossRef] [PubMed]

42. Yoshida, T.; Mogami, J.; Yamaguchi-Shinozaki, K. Omics approaches toward defining the comprehensive abscisic acid signaling network in plants. Plant Cell Phys. 2015, 56, 1043-1052. [CrossRef] [PubMed]

43. Kumar, D. Salicylic acid signaling in disease resistance. Plant Sci. 2014, 228, 127-134. [CrossRef] [PubMed]

44. Prikryl, J.; Watkins, K.P.; Friso, G.; van Wijk, K.J.; Barkan, A. A member of the Whirly family is a multifunctional RNA- and DNA-binding protein that is essential for chloroplast biogenesis. Nucleic Acids Res. 2008, 36, 5152-5165. [CrossRef] [PubMed]

45. Krupinska, K.; Oetke, S.; Desel, C.; Mulisch, M.; Schaefer, A.; Hollmann, J.; Kumlehn, J.; Hensel, G. WHIRLY1is a major organizer of chloroplast nucleoids. Front. Plant Sci. 2014, 5. [CrossRef] [PubMed]

46. Zhu, J.; Tremblay, N.; Liang, Y. Comparing SPAD and atLEAF values for chlorophyll assessment in crop species. Can. J. Soil Sci. 2012, 92, 645-648. [CrossRef]

47. Schreiber, U.; Bilger, W.; Neubauer, C. Chlorophyll fluorescence as a nonintrusive indicator for in vivo photosynthesis. In Ecophysiology of Photosynthesis, 1st ed.; Schulze, E.D., Cladwell, M.M., Eds.; Springer: Berlin, Germany; Heidelberg, Germany, 1995; Volume 100, pp. 49-70.

48. Genty, B.; Briantais, J.M.; Baker, N.R. The relationship between the quantum yield of photosynthetic electron transport and quenching of chlorophyll fluorescence. Biochim. Biophys. Acta 1989, 990, 87-92. [CrossRef]

49. Chomczynski, P.; Mackey, K. Modification of the TRI reagent procedure for isolation of RNA from polysaccharide- and proteoglycan-rich sources. Biotechniques 1995, 19, 942-945. [PubMed]

50. Livak, K.J.; Schmittgen, T.D. Analysis of relative gene expression data using real-time quantitative PCR and the $2^{-\Delta \Delta C T}$ method. Methods 2001, 25, 402-408. [CrossRef] [PubMed]

51. Gendrel, A.V.; Lippman, Z.; Yordan, C.; Colot, V.; Martienssen, R.A. Dependence of heterochromatic histone H3 methylation patterns on the Arabidopsis gene DDM1. Science 2002, 297, 1871-1873. [CrossRef] [PubMed]

52. Johnson, L.M.; Cao, X.; Jacobsen, S.E. Interplay between two epigenetic marks: DNA methylation and histone H3 lysine 9 methylation. Curr. Biol. 2002, 12, 1360-1367. [CrossRef]

(C) 2016 by the authors; licensee MDPI, Basel, Switzerland. This article is an open access article distributed under the terms and conditions of the Creative Commons Attribution (CC-BY) license (http:/ / creativecommons.org/licenses/by/4.0/). 